\title{
New Perspectives for Mucolytic, Anti-inflammatory and Adjunctive Therapy with 1,8-Cineole in COPD and Asthma: Review on the New Therapeutic Approach
}

Lisa Joy Juergens · Heinrich Worth - Uwe R. Juergens

Received: January 8, 2020 / Published online: March 21, 2020

(C) The Author(s) 2020

\section{ABSTRACT}

The mucolytic monoterpene 1,8-cineole (eucalyptol), the major constituent of eucalyptus species, is well known for its anti-inflammatory, antioxidant, bronchodilatory, antiviral and antimicrobial effects. The main protective antiviral, anti-inflammatory and mucolytic mechanisms of 1,8-cineole are the induction of interferon regulatory factor 3 (IRF3), the control of nuclear factor kappa-light-chain-enhancer of activated B cells (NF- $\mathrm{kB}$ ) along with decreasing mucin genes (MUC2, MUC19). In normal human monocytes direct inhibition was shown of reactive oxygen species (ROS)-mediated mucus hypersecretion and of steroid resistence inducing superoxides $\left(\mathrm{O}_{2}^{-}\right)$and pro-inflammatory hydrogen peroxides $\left(\mathrm{H}_{2} \mathrm{O}_{2}\right)$ with partial

Digital Features To view digital features for this article go to https://doi.org/10.6084/m9.figshare.11876436.

U. R. Juergens $(\varangle)$

Department of Pulmonary Rehabilitation, Asklepios

Nordseeklinik Westerland, Norderstraße 81, 25980

Sylt, Germany

e-mail: Uw.Juergens@asklepios.com;

juergens_uwe@t-online.de

L. J. Juergens

Medical University of Tübingen, Medical School,

72070 Tübingen, Germany

e-mail: lisa.joy@juergensfamily.de

H. Worth

Specialist Forum Fürth, 90762 Fürth, Germany control of superoxide dismutase (SOD), which enzymatically metabolizes $\mathrm{O}_{2}{ }^{--}$into $\mathrm{H}_{2} \mathrm{O}_{2}$. By inhibition of NF- $\mathrm{KB}, 1,8$-cineole, at relevant plasma concentrations $(1.5 \mu \mathrm{g} / \mathrm{ml})$, strongly and significantly inhibited in normal human monocyte lipopolysaccharide (LPS)-stimulated cytokines relevant for exacerbation (tumour necrosis factor alpha (TNF $\alpha)$, interleukin (IL)-1 $\beta$ and systemic inflammation (IL-6, IL-8). Infectious agents and environmental noxa have access via TNF $\alpha$ and IL- $1 \beta$ to the immune system with induction of bronchitis complaints and exacerbations of chronic obstructive pulmonary disease (COPD), asthma and asthma-COPD overlap. In lymphocytes from healthy human donors 1,8-cineole inhibited TNFa, IL$1 \beta$, IL-4 and IL-5 and demonstrated for the first time control of Th1/2-type inflammation. 1,8Cineole at relevant plasma levels increased additively in vitro the efficacy of inhaled guideline medications of budesonide (BUD) and budesonide + formoterol, and preliminary data also showed increased efficacy of long-acting muscarinic receptor antagonist (LAMA)-mediated cytokine inhibition in vitro. On the basis of the preclinical data, earlier randomised controlled studies with adjunctive therapy of 1,8cineole $(3 \times 200 \mathrm{mg} /$ day) for 6 months showed improvement of uncontrolled asthma by significant improvement of lung function, nocturnal asthma and quality of life scores and in COPD decrease of exacerbations (- 38.5\%) (during wintertime). This review reports an 
update with reference to the literature of 1,8 cineole, also as adjunctive therapy, as a therapeutic agent for the protection and control of inflammatory airway diseases.

Keywords: Asthma; Chronic obstructive pulmonary disease (COPD); Mucolytics; Sinusitis; 1,8-Cineole

\section{Key Summary Points}

This new review focuses on the current status of the monoterpene 1,8-cineole to suggest therapy and adjunctive therapy with 1,8-cineole for inflammatory airway diseases.

It is the first review of the current status of the known pathogenetic mechanisms of inflammatory airway diseases to discuss, in comparison to current guideline recommendations for asthma and COPD, the underlying mechanisms of action and clinical benefits of recommended medications compared to 1,8-cineole alone and as adjunctive therapy for the treatment of COPD, asthma and sinusitis.

Therefore, this is the first review to report on the potential advances in therapy with 1,8-cineole.

\section{INTRODUCTION}

The monoterpene 1,8-cineole (eucalyptol) is chemically a terpenoid oxide that is well known as the major constituent (77-84\%) of various eucalyptus species and also the component of other essential oils with a relevant meaning for clinical effect. Eucalyptus oil is well known for its biological activities, including anti-inflammatory, antioxidant, free radical scavenging, mucolytic/ secretolytic, bronchodilatory, antiviral and antimicrobial effects, as reviewed elsewhere [1]. These effects will be of relevance for the treatment of airway diseases in addition to having antifungal, antiseptic, antispasmodic, analgetic and antitumour properties. Essential oils may vary in their plant concentrations depending on various regional influences, such as agroclimatic conditions [2]; however, 1,8-cineole can be made available in a standardized form for clinical use following extraction from eucalyptus oil.

A further review evaluated the potential biological effects of 1,8-cineole on the most promising targets in the treatment of chronic obstructive pulmonary disease (COPD) in animal experimental models [3]. In this report, 1,8cineole interacted with relevant mediators of pathophysiological pathways of COPD and identified receivers and membrane channels, oxidative stress, transcription molecules and expression of cytokines, cell adhesion molecules and neutrophil chemotaxis, pro-inflammatory cells, proteases and remodelling as potential therapeutic targets. The authors concluded from these findings that eucalyptol $(1,8-$ cineole) showed a relevant additional treatment option to the use of anti-inflammatory drugs in asthma and COPD.

Former and current conventional treatments have long been geared toward relieving symptoms, preventing recurrent exacerbations, preserving optimal lung function and enhancing the overall quality of life [4]. Because asthma and COPD are chronic inflammatory diseases, it is essential to determine whether new approaches with anti-inflammatory and antioxidant agents can halt or slow the decline in lung function that occurs in response to the disease when selecting candidate drugs. In this regard, the consensus of a group of Chinese pulmonary physicians [5] and a collaborative task force between the European Respiratory Society and the American Thoracic Society (ERS/ATS guidelines) [6] was focused on the prevention of excerbations in COPD by mucolytics, macrolides, long-acting muscarinic receptor antagonists (LAMAs)/long-acting $\beta_{2}$-agonists (LABAs) in stable COPD and the phosphodiesterase (PDE)-IV inhibitor roflumilast in COPD with associated bronchitis. Selected thresholds by the task force for clinically important differences included relative risk reductions of mortality (15\%), exacerbations (20\%), adverse events 
(15\%) and a four-point reduction on the St. George's Respiratory Questionnaire (SGRQ) with complete medications for COPD to determine the add-on effect. A review and six randomized studies of at least 1 year with $N$ acetylcysteine (NAC), carbocysteine and ambroxol in patients with COPD (forced expiratory volume in $1 \mathrm{~s}$ (FEV1) 30-79\%), with at least two exacerbations per year during the previous 2 years, were evaluated. Hospitalizations and COPD exacerbations were reduced (rate ratio 0.79) with a stronger effect of highdose (e.g. NAC $600 \mathrm{mg}$ twice daily) mucolytic therapy (rate ratio $0.69,95 \%$ CI $0.50-0.94$ ), compared to low-dose mucolytic therapy with no significant reduction (rate ratio $0.87,95 \% \mathrm{CI}$ 0.66-1.14) and no increase of adverse effects.

This article is based on previously conducted studies and does not contain any studies with human participants or animals performed by any of the authors. It is the first review to report on the current knowledge of the known mucolytic agent 1,8-cineole (eucalyptol) with regard to its anti-inflammatory, antioxidant and antimicrobial activities for the treatment of inflammatory airway diseases. In particular, the importance of 1,8-cineole as adjunctive therapy to control systemic inflammation and to interact with guideline medications for COPD and asthma by its exhaled availability via the peripheral airways will be discussed.

\section{APPROVED EFFICACY OF 1,8- CINEOLE IN RANDOMIZED, PLACEBO-CONTROLLED TRIALS}

Chronic rhinosinusitis is a well-known risk factor (hazard ratio 3.7) for 30-day readmission due to frequent exacerbations of asthma and COPD and outpatient management of the upper and lower airways is recommended $[7,8]$.

The highest odds ratios (OR) for exacerbated asthma were reported for symptoms of chronic bronchitis (2.70) and sinusitis (1.5) besides other comorbidities. In perennial allergic rhinitis with seasonal exacerbations (PARSE study), symptoms of rhinitis were reportedly worse in difficult-to-control vs. easy-to-control asthma, and seasonal patterns also partially corresponded to those of difficult-to-control asthma [9]. The first placebo-controlled study with 1,8-cineole (two $100 \mathrm{mg}$ capsules three times daily for 7 days) in acute non-purulent sinusitis showed significant reduction of the mean symptoms sum-score after 4 and 7 days and amelioration of headache of secondary end points [10]. The effect of 1,8-cineole on controlling mucus hypersecretion was studied in a model of experimental rhinosinusitis on lipopolysaccharide (LPS)-stimulated nasal slice cultures ex vivo and showed for the first time significant decrease in the number of mucinfilled goblet cells with reduction of the mucin genes MUC2 and MUC19 in association with significantly attenuated nuclear factor kappalight-chain-enhancer of activated B cells (NF$\kappa B)$ activity [11]. Since the common cold is known as the most frequent reason for virusexacerbated upper and lower inflammatory airway diseases, such as acute and chronic rhinosinusitis in the context of frequent exacerbations of COPD and asthma, the same group also found that 1,8-cineole induced activity of the antiviral transcription factor interferon regulatory factor 3 (IRF3) in the presence of its inhibitory effect on pro-inflammatory NF- $\kappa \mathrm{B}$ signalling [12].

At this stage of our knowledge, seasonal or permanent daily adjunctive therapy with 1,8cineole for the protection of exacerbated airway disease of the upper and lower airways is to be recommended, especially in the presence of increased risks of sinusitis with existing asthma, asthma-COPD overlap and COPD.

In the first preliminary placebo-controlled study in severe steroid-dependent asthma $(n=$ 32 ), following a run-in phase of 2 months to determine the minimal effective dose of daily prednisolone, patients were randomly allocated to receive either 1,8-cineole $(3 \times 200 \mathrm{mg} /$ day $)$ (Soledum $^{\circledR}$ forte capsules, registered in various European countries, also available as Soledum addicur capsules registered in Germany since 1 November 2019), or placebo, while daily prednisolone was reduced by $2.5 \mathrm{mg}$ every 3 weeks [13]. Results showed for the first time significant prednisolone reduction of $36 \%$ with active treatment (range $2.5-10 \mathrm{mg}$, mean 3.75) vs. a decrease of only $7 \%(2.5-5 \mathrm{mg}$, mean 
$0.91 \mathrm{mg}$ ) in the placebo group. These results suggested a prednisolone equivalent potency of 1,8 -cineole $600 \mathrm{mg}$ of around $2.8 \mathrm{mg}$ that was well tolerated following steroid reduction. In a first double-blind, placebo-controlled multicentre study of patients $(n=247)$ with wellcontrolled asthma (FEV1 82\%) on inhaled medication guidelines, the effects of adjunctive therapy with 1,8 -cineole $(3 \times 200 \mathrm{mg} /$ day $)$ on improvement of lung function and Asthma Quality of Life Questionnaire (AQLQ) were studied for 6 months [14]. FEV1 increased significantly in the cineole group $(310 \mathrm{ml})$ compared to the placebo group $(200 \mathrm{ml})$, and also some scores of nightly asthma and AQLQ improved significantly. Caution is advised in asthmatics with severe perfume incompatibility since 1,8-cineole is exhaled.

A randomized study in acute bronchitis $(n=$ 242 ) with 1,8-cineole over 10 days showed significant improvements after 4 days of the bronchitis severity-sum score compared to placebo [15]. Concomitant therapy with 1,8-cineole (two capsules of $100 \mathrm{mg}$ three times daily) was also studied in a placebo-controlled study $(n=242)$ in COPD (Global Initiative for Chronic Obstructive Lung Disease (GOLD) II-III) with a primary outcome of reduction of exacerbations, and a secondary outcome of changes in lung function, respiratory symptoms and quality of life scores during 6 months [16]. Basic medication consisted of LABA, inhaled corticosteroids (ICS), anticholinergics and theophylline. All patients were current smokers or ex-smokers with at least 10 pack-years. In the group treated with 1,8-cineole, the number of exacerbations was significantly $(p<0.036)$ reduced by $38.5 \%$, as were the severity and duration, FEV1 increased by $78 \mathrm{ml}$ in the range of clinical significance and the improvement in SGRQ scores almost reached significance $(p=0.063)$. Results of this first controlled study in COPD suggest new evidence of the superior therapeutic efficacy of adjunctive therapy with 1,8-cineole to control COPD exacerbations compared to combined inhaled therapies with LABA + ICS alone.

According to the German Guideline for COPD [17], 1,8-cineole is recommended in addition to other mucolytics for its expectorant activity in dyscrinemic mucus. The guideline also recommends that substances with anti-inflammatory and antioxidant effects can be used to reduce exacerbations in patients with COPD and frequent exacerbations and points out that 1,8-cineole has been shown to significantly reduce exacerbations in patients with COPD and frequent exacerbations.

\section{ANTI-INFLAMMATORY PROFILE AND MODE OF ACTION OF 1,8- CINEOLE}

Inflammation is well known as a protective response to airway injury due to infections and various inhaled agents and to induce airway repair by the activation of many pathways, with the release of multiple inflammatory mediators that may often be excessive to induce chronic airway inflammation [18] characteristic of COPD, asthma and sinusitis. The acute and often chronic persisting clinical symptoms are airway hypersecretion and breathing symptoms that are caused by various mediators, such as matrix metalloproteinases (MMP-9), vascular cell adhesion molecules (VCAM-1), cyclooxygenase-2 (COX-2), cytosolic phospholipase $\mathrm{A}_{2}$ $\left(\mathrm{CPLA}_{2}\right)$ and LPS [19]. Various pro-inflammatory stimuli such as reactive oxygen species (ROS) from cigarette smoke [20], airway infections and inflammatory processes are linked with increased release of cytokines/chemokines (tumour necrosis factor alpha (TNF $\alpha)$, interleukin (IL)-1 $\beta$, IL-6, IL-8). These cytokines, as clinical markers of increased mucus production, exacerbations and steroid resistance, induce NF- $\kappa \mathrm{B}$ [21], which is also produced by activation of NF$\kappa \mathrm{B}$ in response to oxidative stress [22]. These processes promote induction of airway hyperresponsiveness and the expression of inflammatory genes with relevance in airway diseases. Beyond these interactions, overprotection against ROS by cytokine-induced excessive stimulation or mitochondrial activation and of the nicotinamide adenine dinucleotide phosphate (NADPH oxidase) system in phagocytes is important for bacterial killing. In this regard, it is of interest that current guidelines for inhaled 
therapies do not directly control ROS production.

Original articles on natural products and reviews on plant species of different herbs containing the monoterpene 1,8-cineole besides other terpenes report on the anti-inflammatory and antioxidant activities in various models [23-25]. Pro-inflammatory cytokines, such as TNF $\alpha$, IL-1 $\beta$, IL-6, IL-8, and COX-2, are known to be expressed following the dissociation of the inhibitory protein kappa-light-chain-enhancer of activated B cells (Iкb $\alpha$ ) from the NF- $\mathrm{B}$ B subunits p65 and its translocation from the cytoplasm to the nucleus, which is controlled by various essential oils and their major compounds as promising agents for the treatment of chronic inflammation [26, 27]. The central, anti-inflammatory mechanism of action of 1,8cineole and potentially various other terpenes is the induction of I $\mathrm{kb} \alpha$ and the prevention of NF$\kappa \mathrm{B}$ translocation with the consequent control of pro-inflammatory mediator production [28]. In addition, in an animal model of LPS-induced pulmonary inflammation, 1,8-cineole increased the anti-inflammatory cytokine IL-10 in lung tissues besides inhibiting TNF $\alpha$, IL- $1 \beta$ and reducing expression of NF-kB's subunit p65 [29]. Therefore, preventing NF- $\kappa \mathrm{B}$ nuclear translocation is recommended as the potential therapeutic target of the antioxidant and antiinflammatory monoterpene 1,8-cineole. There is further evidence that 1,8-cineole also acts as an analgesic and anti-inflammatory agent by stimulating the thermosensitive, cool temperature-detecting transient receptor (TRP) cation channels (TRPM8) and by inhibiting the human transient receptor potential cation channel, subfamily A, member 1 (TRPA1), a known sensor of noxious cold [30].

The anti-inflammatory activity of 1,8-cineole was studied in various preclinical studies using in vitro and ex vivo models from normal human subjects and in patients with asthma and in animal models. We reported for the first time in healthy subjects and in patients with asthma the inhibition of arachidonic metabolism of leukotriene $\mathrm{B}_{4}$ $\left(\mathrm{LTB}_{4}\right)$ and prostaglandin $\mathrm{E}_{2}\left(\mathrm{PGE}_{2}\right)$ of ex vivo cultured monocytes as the first hint of the anti-inflammatory mode of action of 1,8- cineole (Soledum ${ }^{\circledR}$ forte capsules) taken orally for 4 days, with a regression 4 days after completion of therapy [31]. These results also showed for the first time a relevant systemic anti-inflammatory effect of 1,8-cineole after oral ingestion of $3 \times 200 \mathrm{mg} /$ day of Soledum ${ }^{\circledR}$ forte capsules for 4 days. Early in vitro studies further reported that 1,8-cineole decreased (by more than $60 \%$ ) the production of TNF $\alpha$, IL-1 $\beta$, IL-6 and IL-8 in monocytes [32] and of $\mathrm{TNF} \alpha, \quad$ IL-1 $\beta$, IL-4 and IL-5 in lymphocytes [32] from healthy human donors and controls Th2-type inflammation and Th1/Th2 balance, which is now controlled downstream in eosinophilic asthma by IL-5 inhibitors and receptor antagonists [33]. In these studies, 1,8-cineole showed for the first time a steroidlike inhibitory effect on stimulated cells in vitro at the relevant concentration of $10^{-5} \mathrm{M}(1.5 \mu \mathrm{g} / \mathrm{ml})$ equivalent to the plasma level after taking $3 \times 200 \mathrm{mg}$ of 1,8-cineole for 14 days [34] [Pidgeon AW. Expert report on the pharmacokinetics (phase I) of cineole. 1993 (not published)]. This should be taken into account regarding several animal studies using much higher concentrations in relation to body weight. Furthermore, a previous study evaluated that around $20 \%$ of orally taken 1,8-cineole reaches the peripheral airways and is then exhaled [35]. Besides the known systemic anti-inflammatory effects in the blood as a volatile organic compound, 1,8-cineole also reaches the peripheral lung, which is not possible by currently available inhaled therapies for asthma and COPD. When 1,8-cineole is exhaled it also reaches the paranasal sinuses, which can benefit only to a limited extent from low blood circulation of orally administered medications. In a recent study on a house dust mite (HDM)stimulated in vitro model of bronchial epithelial cells and an HDM-induced murine asthma model of inhaled 1,8-cineole, Dermatophagoides pteronyssinus stimulated IL-8, IL-6, granulocyte macrophage-colony stimulating factor (GM-CSF) and induced airway hyper-responsiveness (AHR). In this approach, the numbers of eosinophils in bronchoalveolar lavage fluid (BAL) and of IL-4, IL-13 and IL-17A were significantly reduced by 1,8 - 
cineole [36]. A recent study that investigated BAL cytokine profiles in healthy subjects compared to those in controlled and uncontrolled asthma showed increased production of various cytokines (IL-1 $\beta$, IL-5, IL-6, IL-8 etc.) and of eosinophils and granulocytes in patients with asthma as compared to patients without asthma, whereas non-controlled asthma was distinguished from controlled asthma only by neutrophil percentage and IL8 levels, which correlated with FEV1 [37]. In eosinophils, high asthma levels of IL-5, IL-13, IL-16 etc. were higher in the presence of the same neutrophil percentage, IL-8 and of FEV1, indicating the role of neutrophils and IL-8 in uncontrolled asthma with inverse correlation to lung function [38]. In smokers with COPD and preserved spirometry (postbronchodilator FEV1/forced vital capacity $($ FVC) $>0.70)$, systemic inflammatory markers of IL-6-induced C-reactive protein (CRP) were associated with a greater number of exacerbations and increased symptom burden (CAT), while increased TNF $\alpha$ correlated with an elevated CAT score and CRP and were negatively correlated with 6-min walking distance (6MWD) [39]. These data underline again the important correlation, even in early stages COPD, of TNF $\alpha$ and IL-6 (CRP), as markers of systemic inflammation, for the progressive symptomatic burden of the COPD.

In this regard a recently published in vitro study of cultured human monocytes from normal, non-smoking subjects showed, at relevant systemic concentrations of 1,8-cineole (0.15-1.5 $\mu \mathrm{M})$, dose-dependent inhibition of IL6 $>$ IL1 $\beta>$ IL- $8 \geq \mathrm{TNF} \alpha$, with complete inhibition at therapeutic concentration $(1.5 \mu \mathrm{M})$ and partial inhibition (20-40\%) of IL-1 $\beta$ and IL- 6 at the exhaled concentration $(0.3 \mu \mathrm{M})$ [40]. These data showed for the first time dose-dependent antiinflammatory activities of 1,8-cineole at clinically relevant systemic and also exhaled concentrations, since in LPS-stimulated cultured human monocytes 1,8-cineole demonstrated the strongest inhibitory effect of $100 \%$ on IL- 6 at the lowest and almost half the plasma concentration $(0.6 \mu \mathrm{M})$ [40].
A new study reports the importance of epithelial IL-6 trans-signalling, in the absence of systemic inflammation, as a new asthma phenotype with frequent exacerbations, blood eosinophilia and increased airway inflammation with infiltration of $\mathrm{T}$ cells and macrophages [41].

In summary, this current knowledge reported 1,8-cineole as a Th1/Th2 cytokine immunomodulator by its anti-inflammatory and antioxidant activities to control systemic inflammation, disease progression, the rate of exacerbations, steroid resistance and potentially protective effects against increasing development of lung emphysema in inflammatory airway diseases. So far, the current state of knowledge suggests that not only as a mucolytic/secretolytic drug but also by its multifunctional mechanisms 1,8-cineole controls the cause of mucus production with a peripheral and systemic availability as compared to inhaled medications, suggesting the adjunctive therapy with 1,8-cineole for COPD, asthma and sinusitis [42] (Fig. 1).

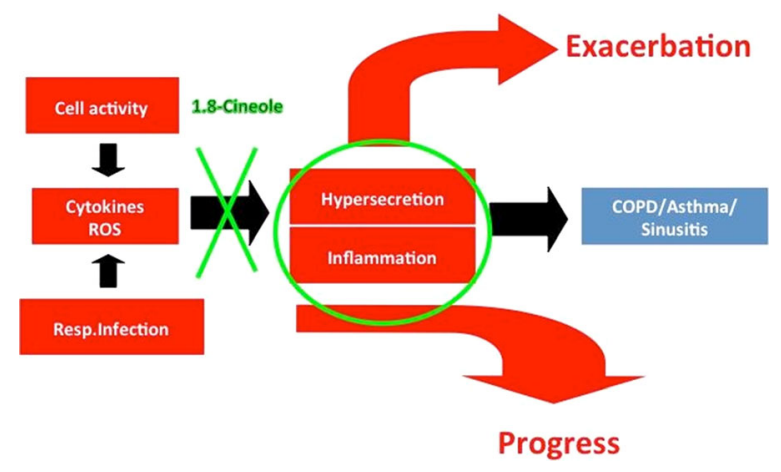

Fig. 1 Various inhalable pollutants as well as viruses and bacteria induce or intensify pre-existing airway inflammation. The result is the release of oxygen radicals and inflammatory mediators, which cause bronchitis with hypersecretion and acute respiratory distress, depending on the type of inflammation and genetic determinism. As a result of the at least bifunctional anti-inflammatory and antioxidant efficacy profile of 1,8-cineole, this is not only a symptomatic but also a causative therapy for the treatment of bronchial complaints. Through this approach, mucus hypersecretion and recurrent exacerbations are directly controlled with the aim to reduce the progression of chronic respiratory diseases 


\section{ANTIOXIDANT ACTIVITY OF 1,8- CINEOLE AND CONTROL OF REDOX BALANCE FOR ADJUNCTIVE THERAPY IN COPD AND ASTHMA}

Oxidative stress and oxidant/antioxidant, protease/antiprotease imbalance have a major impact on the severity of symptoms and disease progression [43]. Oxidative stress is caused by various ROS, in particular by $\mathrm{O}_{2}{ }^{--}$from cigarette smoke or by the degree of pulmonary and systemic inflammation responses as produced by macrophages and neutrophils [44]. $\mathrm{O}_{2}{ }^{-}$is further metabolized by superoxide dismutases (SOD) to $\mathrm{H}_{2} \mathrm{O}_{2}$, with a further breakdown by catalases [45]. Since $\mathrm{H}_{2} \mathrm{O}_{2}$ is also inhaled with cigarette smoke and is increased when exhaled, control of $\mathrm{H}_{2} \mathrm{O}_{2}$ would be desirable in COPD [46], which promotes inflammatory airway responses by the initiation of cytokine production. Furthermore, a controlled clinical study $(n=182)$ reported decreased levels of ascorbic acid in smokers and a considerable recovery by $25 \%$ after 4 weeks of smoking cessation [47]. A completed European survey $(n=680)$ followed the effect of dietary antioxidants for 10 years on lung function according to documented food and vitamin intake and smoking status, and reports improvements in lung function decline (FEV1 - $3.7 \mathrm{ml} /$ year; FVC - $4.5 \mathrm{ml}$ /year), particularly in ex-smokers [48]. Since current standard guideline medications of LABA, ICS and of LAMA only have at most very limited antioxidant effects, it would be of interest to explore the potential antioxidant activity of the monoterpene 1,8-cineole for further potential co-medication.

Recent in vitro studies on the antioxidant activity of essential oils reported scavenging activity against ROS [49], ROS effects on antioxidant enzymes (catalases, SOD, glutathione reductase (GR), heme oxygenase 1 (HO1), glutathione peroxidase (GPx)) induced by $\mathrm{H}_{2} \mathrm{O}_{2}$ [50], nitrogen oxide (NO) and myeloperoxidase (MPO) production by $\mathrm{H}_{2} \mathrm{O}_{2}-$ stimulated neutrophils [51]. One publication showed for the first time the antioxidant profile of 1,8-cineole, at relevant plasma concentrations $\left(\leq 1.5 \mu \mathrm{g} / \mathrm{ml} ; 10^{-5} \mathrm{M}\right)$ in foetal calf serum (FCS)-stimulated normal human monocytes in vitro, with significant inhibition of $\mathrm{O}_{2}^{--}\left(10^{-5} \mathrm{M}:-53 \%\right)$, SOD (concentration independent: $-28 \%)$ and of $\mathrm{H}_{2} \mathrm{O}_{2}\left(10^{-10} \mathrm{M}\right.$ : $-48 \%$ ) [52] (Fig. 2). These data showed for the first time control of $\mathrm{O}_{2}^{--}$production without complete inhibition, by virtue of necessary antibacterial activity with only partial control of SOD to allow the controlled metabolism of $\mathrm{O}_{2} \cdot{ }^{--}$into pro-oxidant and pro-inflammatory $\mathrm{H}_{2} \mathrm{O}_{2}$, which is also directly controlled at very low concentrations of systemic and exhaled concentrations of 1,8-cineole.

LPS-stimulated 8-isoprostane (8-Isop) as a marker of total antioxidant activity was dosedependently $\left(10^{-6} \mathrm{M}\right.$ : $\left.-42 \% ; 10^{-5} \mathrm{M}:-84 \%\right)$ inhibited [52]. This is of interest since exhaled 8-Isop became known as an in vivo biomarker of lung oxidative stress in patients with COPD and healthy smokers [53]. On the basis of these results, the most promising approach in repeatedly exacerbated COPD or steroid-dependent asthma is reversal of corticosteroid resistance through increasing histone deacetylase 2 (HDAC2) activity, where 1,8-cineole should be recognized as a more effective

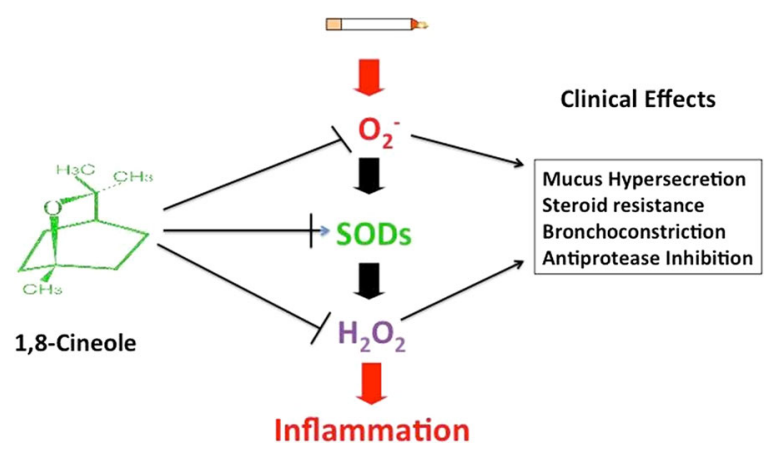

Fig. 2 Cigarette smoke is rich in oxygen radicals that induce bronchial hypersecretion and, among other activities, steroid resistance. Oxygen radicals $\left(\mathrm{O}_{2}{ }^{-}\right)$are degraded via the activity of superoxide dismutases (SOD) to hydrogen peroxide $\left(\mathrm{H}_{2} \mathrm{O}_{2}\right)$, which induces bronchial inflammation. In vitro studies of foetal calf serumstimulated human monocytes showed modulating antioxidant effects of therapeutically relevant concentrations of 1,8-cineole with approximately $50 \%$ inhibition of $\mathrm{O}_{2}{ }^{--}$ and $\mathrm{H}_{2} \mathrm{O}_{2}$ and a partial inhibition in this approach of SOD [52] 
antioxidant with additional anti-inflammatory activities [54].

$\mathrm{O}_{2}{ }^{--}$radicals are inhaled and released from activated inflammatory cells during exacerbations as the most putative risk factors to stimulate bronchial hypersecretion and inflammatory airway responses in COPD and asthma, in addition to their pro-carcinogenic activities. In moderate COPD (GOLD II, $n=23$ ) the antioxidant capacity of the natural thiolcontaining antioxidants GPx was reduced and in severe COPD (GOLD III, $n=56$ ) the antioxidant lipid peroxidation product malondialdehyde (MDA) was significantly higher than in moderate COPD [55]. These results suggested an association between oxidative stress and obstructive lung impairment as a measure of COPD severity. An earlier controlled study in mice exposed to cigarette smoke (CS) for 5 days reported for the first time that CS-induced acute lung inflammation of increased metalloprotease 12, TNF $\alpha$ and NF- $\kappa$ B activation was reduced by non-thiol compound supplementation with the vitamins ascorbic acid and $\alpha$-tocopherol [56]. In this regard, recent results from a mouse model of intermittent hypoxia, relevant for severe COPD, showed increased ROS production and elastase activity that could be controlled by antioxidative L-glutathione and the TNF $\alpha$ antagonist infliximab [57]. In various in vitro and animal studies with essential oils 1,8 -cineole was reported as the main antioxidant compound [58, 59]. Short-term exposure to inhaled eucalyptol (3 mg, $10 \mathrm{mg}$ for 5 days) in a mouse model decreased oxidative stress by the inhibition of ROS, SOD, catalase and MDA, and showed anti-inflammatory efficacy by the inhibition of NF-kB's p65 subunit and of IL-1 $\beta$, IL- 6 and of TNF $\alpha$ at the highest concentration of $10 \mathrm{mg} /$ day, suggesting relevant antioxidative and anti-inflammatory activities [60]. In this report, 1,8-cineole promoted lung repair at higher doses with de novo formation of alveoli as compared to the control group. In this study, lung regeneration by 1,8-cineole resulted in the upregulation of elastin, tissue inhibitor of matrix metalloproteinase (TIMP-1) and antioxidant, anti-inflammatory protective effects by the reduction of anti-inflammatory (MPO, $\mathrm{TNF} \alpha$, IL-1 $\beta$, IL-6 etc.) and redox marker levels.
Using a similar design, a further study with inhaled concentrations of eucalyptus oil $(10-300 \mathrm{mg} / \mathrm{kg})$ also reports prevention of lung injury [61]. A new review is focusing on the importance of controlling various disease mechanisms of oxidative stress in chronic respiratory diseases (CRDs) including asthma, COPD, respiratory infections, and also lung cancer, which are not sufficiently controlled by available anti-inflammatory therapies, such as ICS, LABAs, NF- $\kappa$ B inhibitors, mitogen-activated protein kinase p38 (MAPK p38) inhibitors and PDE-IV inhibitors with no effect on disease progression in COPD [62]. Although ICS are the basic medications for control of airway inflammation in asthma, glucocorticosteroids were not effective in preventing oxidative stress-mediated airway inflammation by steroid-related interference with anti-inflammatory gene expression and antioxidant enzymes [63].

To summarize, current knowledge on the role of a balanced ratio of oxidants and antioxidants, especially in the pathophysiology of COPD and asthma, has suggested the importance of effective antioxidant therapy in inflammatory airway diseases. Since standard therapies with LABA + ICS seem not to provide any antioxidant effects, compensation with adjunctive therapy with 1,8-cineole is an option for achieving relevant antioxidant effects of standard inhaled therapies for the lungs.

\section{ANTIMICROBIAL AND ANTIVIRAL EFFECTS OF 1,8-CINEOLE AND ESSENTIAL OILS}

There is increasing knowledge on the role of the respiratory microbiome in lower and upper airway disease, which may have an impact on disease severity, in particular with the frequency of exacerbations and the underlying disease phenotype [64]. Changes to the airway microbiome by external viral and bacterial infections could potentially induce microbial dysbiosis with clinical relevance of interactions with inflammatory airway-induced exacerbations [65]. In this regard long-term treatment in controlled clinical studies with the antibiotic and anti-inflammatory-acting azithromycin 
showed improvement of exacerbations and disease severity in severe COPD [66] by the downregulation of various antigen-regulating genes and of inflammatory $\mathrm{T}$ cell responses in various inflammatory pathways [67]. Also Global Initiative for Asthma (GINA) guidelines recommend the use of the antibiotic and antiinflammatory azithromycin as co-medication (500 mg three times weekly) in Th1-type inflammation for neutrophilic, uncontrolled asthma, with, however, no significant effect on total bacterial load [68]. 1,8-Cineole was also reported to protect against influenza viral infections in mice and virus-induced pulmonary cytokine production of IL-1 $\beta$, IL- 6 and TNF $\alpha$ by the control of NF-kB p65 expression [28] and the induction of the antiviral transcription factor inteferon regulatory factor 3 (IFR3) [12].

New research directly focusing on the antimicrobial activity of various eucalyptus oils with the main component of 1,8-cineole, ranging from $66.93 \%$ to $97.3 \%$, inhibited or killed in vitro the majority of microorganisms [69]. Furthermore, both Eucalyptus globulus essential oil and 1,8-cineole prevented biofilm formation by methicillin-resistant Staphylococcus aureus (MRSA) and subsequently the spreading of nosocomial infection. A recent study reports genetic downregulation of biofilm induction in chronic rhinosinusitis by 1,8 -cineole with inhibition of relevant microbial pathogens (S. aureus, Escherichia coli, Moraxella catarrhalis) and pro-inflammatory NF- $\mathrm{KB}$ target genes at relevant concentrations [70]. This may be of further relevance, since in another study the microbiome profile was assessed by using sequencing of the $16 \mathrm{~S}$ rRNA gene for the followup of hospitalized patients with acute exacerbated COPD (AECOPD) who did not survive with higher Staphylococcus levels [71]. A former study of the pharmacokinetics of inhaled 1,8cineole in humans showed peak plasma concentrations after $18 \mathrm{~min}$, with a biphasic mean distribution of $6.7 \mathrm{~min}$ and an elimination halflife of $104.6 \mathrm{~min}$ [72]. Besides the oral route, application of 1,8-cineole by vapour inhalation has been suggested for exacerbated purulent and non-purulent bronchitis, asthma and COPD owing to its long history of usage and good safety record [73]. In a recent comprehensive in vitro study, the monoterpene 1,8cineole was demonstrated as the major compound (up to $70.4 \%$ ) of different eucalyptus oils that were investigated for the minimal inhibition concentration (MIC) and the minimum bactericidal concentration (MBC) to kill 99.4\% of bacterials after incubation for 18-24 h [74]. In this study, eucalyptus species with a content of 1,8 -cineole of $42-70.4 \%$ showed antibacterial activities of $8.1-27.4 \%$ against Haemophilus influenzae, Klebsiella pneumoniae, Pseudomonas aeruginosa, S.aureus, Streptococcus agalactiae, Streptococcus pneumoniae and Streptococcus pyogenes compared to various antibiotics (19.9-37.5\%). Also antifungal and antiviral activities were reported for these eucalyptus species, however with generally only a minimal chance for the development of resistance compared to antibiotics. Such data would be of great interest, since $16 \mathrm{~S}$ ribosomal RNA gene sequencing and host gene expression analyses by quantitative real-time PCR actually showed associations between host gene expression and microbiota lung profiles by correlation of the severity of COPD (GOLD III-IV) and potentially the course of the disease. In vitro studies on the sensitivity of microbes to various species of eucalyptus oils with a major content of 1,8-cineole were reviewed [75]. In summary, current data suggest a clinical relevant antiviral and antibacterial activity of 1,8-cineole.

\section{SUMMARY: AT LEAST BIFUNCTIONAL ACTIVITIES OF 1,8- CINEOLE TO IMPROVE COPD AND ASTHMA UNDER GUIDELINE THERAPIES}

In a previous report 1,8-cineole was shown for the first time to induce additively the anti-inflammatory efficacy of ICS and of combined inhaled therapies of LABA + ICS in vitro at the approximate airway concentrations of exhaled 1,8-cineole [40]. Additionally, a recent publication reports for the first time on the antioxidant effects of 1,8-cineole with a highly superior suppression of $\mathrm{O}_{2}^{--}(-53 \%)$ at a relevant 
plasma concentration $\left(10^{-5} \mathrm{M}\right)$ as compared to the strongest effects of budesonide (BUD) $\left(10^{-9} \mathrm{M}:-10.5 \%\right)$ and formoterol $(\mathrm{F})\left(10^{-10} \mathrm{M}\right.$ : $-10.8 \%$ ) alone [52]. At increasing concentrations $\left(10^{-8} \mathrm{M}\right)$, weak inhibitory effects of BUD and $\mathrm{F}$ changed into significant small pro-oxidative activities with at least no pro-oxidative or antioxidative effects of therapeutically relevant combinations of BUD $+\mathrm{F}$. These results showed that 1,8-cineole has at least two different pharmacological actions in the same molecule as a bifunctional drug besides it bronchodilatory, antimicrobial and other activities for the treatment of inflammatory airway diseases.

Th1-type inflammation in high IL-17 phenotype very often plays a key role in frequently exacerbating neutrophilic asthma and COPD [76], which is also controlled by 1,8 -cineole in addition to its control of Th2-type inflammation [33]. In this regard, adjunctive pulse therapies with azithromycin $(3 \times 500 \mathrm{mg}$ per week $)$ [77] and clarithromycin $(2 \times 500 \mathrm{mg}$ per week $)$ [78] for 1 year are recommended only for these antibiotics to control exacerbations besides known side effects (evidence A) by the current Task Force Report of the GOLD Executive Summary [4]. For other mucolytic (mucokinetics, mucoregulators) and antioxidant agents (NAC, carbocysteine), however, as a result of the partial (IL-6) or missing anti-inflammatory (IL$1 \beta$, IL-8, TNF $\alpha$ ) efficacy of NAC, the antioxidant/anti-inflammatory activity of NAC and carbocysteine seemed to be relevant only in patients not receiving ICS [79]. Evidence of vitamin D supplementation was only reported in patients with COPD and vitamin D deficiency (25-hydroxyvitamin $\mathrm{D}_{3}<25 \mathrm{nmol}$ ) [80], and oxidative stress in severe asthma exacerbations was linked with vitamin $\mathrm{D}$ deficiency, increased release of ROS, TNF $\alpha$ NF- $\kappa$ B expression [81] and downregulated expression of glucocorticoid receptors by $\mathrm{H}_{2} \mathrm{O}_{2}$. For this reason, owing to at least a bifunctional anti-inflammatory/antioxidant mode of action, the monoterpene 1,8-cineole seems to be a more promising adjunctive therapy for COPD and asthma, including the asthma-COPD overlap type (ACO), though clinical studies are still rare. Previous randomised controlled trials on the exacerbation rates in COPD with therapies of LABA + ICS compared to LABA + ICS + 1,8-cineole have shown an add-on effect of 1,8-cineole [14], with a stronger reduction of exacerbations compared to LABA + ICS (Fig. 3). In the cineole study, patients with COPD were enrolled with $80 \%$ on LABA and $23 \%$ on ICS, suggesting a relevant ICS-like effect of the multifunctional 1,8-cineole in real life that might have been even greater in patients with COPD on currently recommended standard medications of LAMA + LABA or LAMA + LABA + ICS. Following antagonism of muscarinic $\mathrm{M}_{1} / \mathrm{M}_{3}$ receptors by tiotropium, inhibition of NF- $\kappa B$ and IL-8 in LPS-stimulated bronchial epithelial cells and airway fibroblasts [82] was shown in addition to the published inhibition of many other cytokines. In a guinea pig model of allergic asthma, combined treatment with a nebulizer concentration of tiotropium $(0.01 \mathrm{mM})$ and ciclesonide $(0.01 \mathrm{mg} /$ $\mathrm{kg}$ ) inhibited eosinophilic airway inflammation and remodelling, which was not shown for the

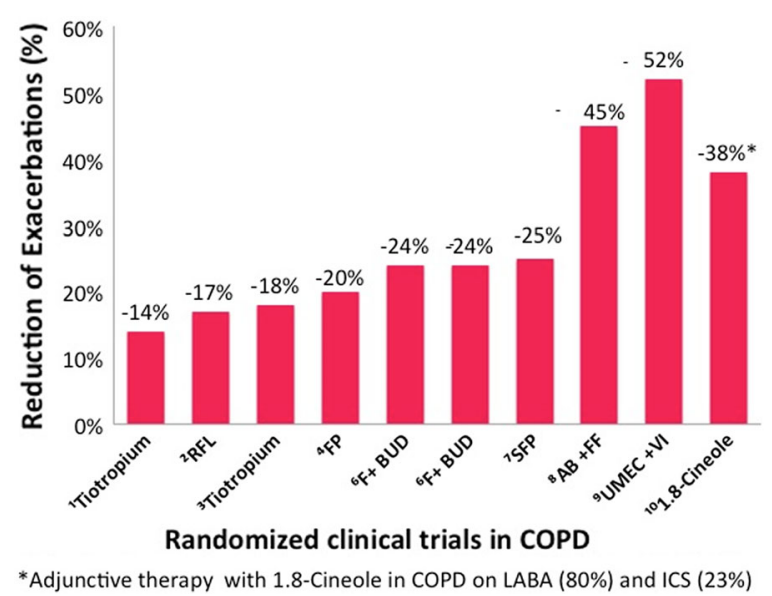

Fig. 3 Previous randomized trials in COPD found a decrease in exacerbation frequency for LABA + ICS in the range of $24 \%$, regardless of the amount of ICS used [85-88], with only a slight difference to ICS alone (20\%) [89]. Studies with monotherapy of a LAMA $[90,91]$ or PDE-IV inhibitor [92] showed comparable reductions (14-18\%) of exacerbations such as ICS alone. In recent studies with LAMA + LABA, however, there a nearly twofold decrease in exacerbations in the range of $50 \%$ has been detected $[93,94]$. For the first time, the effect of adjunctive therapy with the monoterpene 1,8-cineole showed a $38 \%$ decrease in exacerbations 
two substances when administered alone [83]. 1,8-Cineole also showed an airway relaxant effect in a guinea pig model at relevant concentrations (greater than $6.5 \times 10^{-6} \mathrm{M}$ ) with a decreased effect on tracheal hyper-responsiveness to $\mathrm{KCl}$ and carbachol, whereas the effect of acetylcholine $\left(10^{-4} \mathrm{M}\right)$ was only partially controlled at higher concentrations of 1,8-cineole $\left(6.5 \times 10^{-3} \mathrm{M}\right)$, suggesting an additional action on electromechanical coupling [84]. The clinical effect of LAMA, such as that of $\mathrm{M}_{1} / \mathrm{M}_{3}$ antagonism by tiotropium, may be improved by the at least bifunctional anti-inflammatory and antioxidant activity of the mucolytic agent 1,8cineole. Since 1,8 -cineole primarily controls IL$1 \beta$ and $\mathrm{TNF} \alpha$, adjunctive therapy with 1,8 -cineole in inflammatory airway diseases is recommended for the protection of virus-induced $\mathrm{M}_{2}$ receptor dysfunction and to improve the effects of LAMA alone or in combinations with LABA and/or ICS. With respect to the new guideline recommendation for COPD, preliminary in vitro results now show for the first time that 1,8-cineole also controls the pro-inflammatory effects of acetylcholine (ACh), thus improving the anti-inflammatory effects of isolated $\mathrm{M}_{1} / \mathrm{M}_{3}$ receptor antagonism of LAMAs (Fig. 4).

These preliminary results suggest that relevant respiratory and plasma concentrations of 1,8-cineole, at least in the present experimental design, could mediate a comparable or higher anti-inflammatory activity than tiotropium alone and also additively intensifies its anti-inflammatory effects. For this reason, adjunctive therapy with 1,8-cineole is also suggested with LAMA therapy in the early stages of symptomatic COPD (GOLD I-IIB) to control exacerbation and also, potentially, the progression of cigarette smoke-induced neutrophilic and eosinophilic airway inflammation.

\section{LESSONS FOR CLINICIANS}

Inflammatory processes, particularly in COPD, are characterized by only partial therapy responses to ICS, depending on the type of inflammation, such as the COPD-bronchitis type with exposure to CS, inhaled ROS and/or

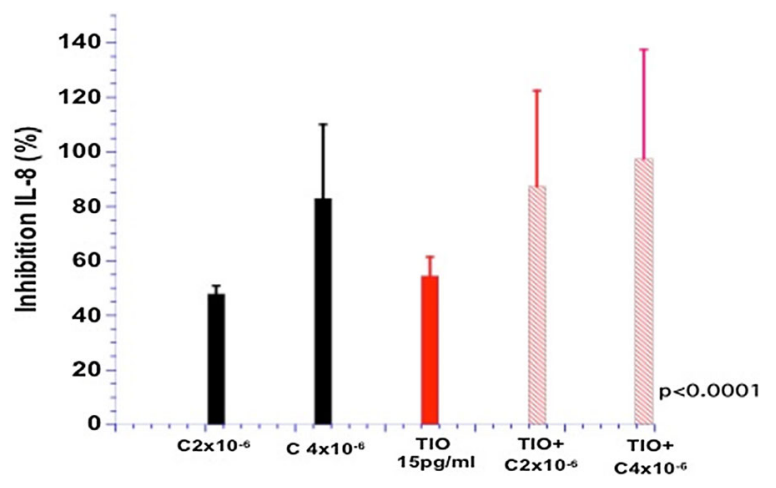

Fig. 4 In an in vitro model $\left(10^{5} / \mathrm{ml}, 2\right.$ Expt., $\left.n=6\right)$ of human monocytes from healthy volunteers (expressing $\mathrm{M}_{1}-\mathrm{M}_{5}$ receptors), the effects of respiratory-relevant concentrations $\left(2 \times 10^{-6} \mathrm{M}\right)$ and a relevant plasma concentration $\left(4 \times 10^{-6} \mathrm{M}\right)$ of 1,8 -cineole $(\mathrm{C})$, tiotropium $15 \mathrm{pg} / \mathrm{ml}$ (TIO) alone and of $\mathrm{TIO}+\mathrm{C}$ after incubation for $20 \mathrm{~h}$ were investigated for IL- 8 in the presence of LPS $(10 \mu \mathrm{g} / \mathrm{ml})$ (Sigma-Aldrich, Germany). Stimulated IL-8 production was inhibited $(p<0.0001$ compared to the LPS control) in a dose-dependent manner, even comparable to tiotropium (TIO) $(15 \mathrm{pg} /$ $\mathrm{ml})$ at a small exhaled and therefore respiratory-relevant concentration of $\mathrm{C}\left(2 \times 10^{-6} \mathrm{M}\right)$. This inhibitory effect of TIO on IL-8 production increased significantly after coincubation with the investigated breath-relevant concentration of $\mathrm{C}$, and further dose-dependently, at an increasing, small systemically relevant concentration $\left(4 \times 10^{-6} \mathrm{M}\right)$

by increased production of exacerbation activated airway cells or the degree and mixture with neutrophilic/eosinophilic Th1/Th2-type inflammation in asthma and ACO. As previously shown $[40,52]$ in vitro, anti-inflammatory and antioxidant effects increased additively by co-incubation of 1,8-cineole + ICS or 1,8cineole + (ICS + LABA), whereas BUD + F at least did not show any pro- or antioxidant activity as shown for $\mathrm{O}_{2}{ }^{--}$. This would suggest a therapeutic value for 1,8-cineole as adjunctive therapy for partial ICS responders by its control of Th1-type inflammation in steroid-resistent asthma, independently of eosinophilia or Th2type inflammation, and of the COPD-bronchitis type, with and without sinusitis, by its bifunctional antioxidant and anti-inflammatory activity, or in patients with asthma, COPD and ACO with frequent exacerbations under 
standard triple therapy. In this regard, it may be of interest that the anti-inflammatory in vitro effect of LAMAs increased in the presence of anti-inflammatory agents, such as 1,8-cineole or ICS, possibly in part by protection against infection or inflammation-induced $\mathrm{M}_{2}$ receptor dysfunction or by improvement of the effects of $\mathrm{M}_{1} / \mathrm{M}_{3}$ receptor inhibition, though the precise mechanism of action seems so far not to be understood. For this reason, a non-steroidal anti-inflammatory substance, such as 1,8-cineole, could be recommended in the early COPD stages of groups without (A) or with (B) clinical symptoms in the known typical range of indication for 1,8-cineole and as adjunctive therapy to LAMA for symptomatic early COPD.

\section{CONCLUSIONS}

Independently of mono- or adjunctive therapy with 1,8-cineole, long-term therapy, because of its antiviral, antibacterial, antioxidant and antiinflammatory activity, is to be recommended besides its effects to control systemic and peripheral lung inflammation, an area that is not generally reachable for standard inhalation therapies.

\section{ACKNOWLEDGEMENTS}

We acknowledge the helpful cooperation of Dr M. Ploch, Cassella-med Ltd, Cologne, Germany and Dr H. Greve, Düsseldorf, Germany.

Funding. The study, rapid service fee and the open access fee was funded by Cassella-med Ltd, Cologne, Germany.

Authorship. All named authors meet the International Committee of Medical Journal Editors (ICMJE) criteria for authorship for this article, take responsibility for the integrity of the work as a whole, and have given their approval for this version to be published.

Authorship Contributions. LJ (medical student) and UJ carried out the literature search and the interpretation of cited data. UJ developed the design and conception of the study. UJ, LJ and HW were involved in drafting and revising the manuscript.

Disclosures. Uwe Juergens was a member of the advisory board at Cassella-med Inc. Lisa Joy Juergens and Heinrich Worth have nothing to disclose.

Compliance with Ethics Guidelines. This article is based on previously conducted studies and does not contain any studies with human participants or animals performed by any of the authors.

Data Availability. Data sharing is not applicable to this article as no datasets were generated or analyzed during the current study.

Open Access. This article is licensed under a Creative Commons Attribution-NonCommercial 4.0 International License, which permits any non-commercial use, sharing, adaptation, distribution and reproduction in any medium or format, as long as you give appropriate credit to the original author(s) and the source, provide a link to the Creative Commons licence, and indicate if changes were made. The images or other third party material in this article are included in the article's Creative Commons licence, unless indicated otherwise in a credit line to the material. If material is not included in the article's Creative Commons licence and your intended use is not permitted by statutory regulation or exceeds the permitted use, you will need to obtain permission directly from the copyright holder.To view a copy of this licence, visit http://creativecommons.org/licenses/by$\mathrm{nc} / 4.0 /$.

\section{REFERENCES}

1. Dhakad AK, Pandey VV, Beg S, Rawat JM, Singh A. Biological, medicinal and toxicological significance of eucalyptus leaf essential oil: a review. J Sci Food Agric. 2018;98:833-48.

2. Jnanesha AC, Ashish K, Vanitha TK. Variation in the yield and chemical composition of eucalyptus species (Nilagiri) under different agro climatic 
condition of India. Int J Herbal Med. 2019;7(1): 04-7.

3. De Lima Gondim F, dos Santos GR, do Nascimento IFMG, Serra DS, Cavalcante FSA. Beneficial effects of eucalyptol in the pathophysiological changes of the respiratory system: a proposal for alternative pharmacological therapy for individuals with COPD. Eur J Med Plants. 2018;25(1):1-10.

4. Siafakas NM, Vermeire P, Pride NB, et al. Optimal assessment and management of chronic obstructive pulmonary disease (COPD). The European Respiratory Society Task Force. Eur Respir J. 1995;8(8): 398-1420.

5. Yan X, Song Y, Shen C, et al. Mucoactive and antioxidant medicines for COPD: consensus of a group of Chinese pulmonary physicians. Int J Chron Obstruct Pulmon Dis. 2017;12:803-12.

6. Wedzicha JA, Calverley PMA, Albert RK, et al. Prevention of COPD exacerbations: a European Respiratory Society/American Thoracic Society guideline. Eur Respir J. 2017. https://doi.org/10. 1183/13993003.02265-2016.

7. Singh U, Wangia-Anderson V, Bernstein JA. Chronic rhinitis is a high-risk comorbidity for 30-day hospital readmission of patients with asthma and chronic obstructive pulmonary disease. J Allergy Clin Immunol Pract. 2019;7(1):279-285.

8. Kariya S, Okano M, Tachibana T, Rikmaru T, Nishizaki K. Lund-Mackay computed tomography score is associated with obstructive pulmonary function changes in chronic cough patients. Am J Rhinol Allergy. 2019;33(3):294-301.

9. Togias A, Gergen PJ, Hu JW, et al. Rhinitis in children and adolescents with asthma: ubiquitous, difficult to control, and associated with asthma outcomes. J Allergy Clin Immunol. 2019;143(3): 1003-11.e10. https://doi.org/10.1016/j.jaci.2018. 07.041.

10. Kehrl W, Sonnemann U, Dethlefsen U. Therapy for nonpurulent rhinosinusitis with cineole: results of a double-blind, randomized, placebo-controlled trial. Laryngoscope. 2004;114(4):738-42.

11. Sudhoff H, Klenke C, Greiner JF, et al. 1,8-Cineole reduces mucus-production in a novel human ex vivo model of late rhinosinusitis. PLoS One. 2015;10(7):e0133040. https://doi.org/10.1371/ journal.phone.0133040.

12. Müller J, Greiner JF, Zeuner M, et al. 1,8-Cineole potentiates IFR3-mediated antiviral response in human stem cells and in ex vivo model of rhinosinusitis. Clin Sci (Lond). 2016;130(15):1339-52.
13. Juergens UR, Dethlefsen U, Steinkamp G, Gillissen A, Repges R, Vetter H. Anti-inflammatory activity of 1,8-cineole (eucalyptol) in bronchial asthma: a double-blind placebo-controlled trial. Respir Med. 2003;97(3):250-6.

14. Worth H, Dethlefsen U. Patients with asthma benefit from concomitant therapy with cineole: a placebo-controlled, double-blind trial. J Asthma. 2012;49(8):849-53.

15. Fischer J, Dethlefsen U. Efficacy of cineole in patients suffering from acute bronchitis: a placebocontrolled double-blind trial. Cough. 2013;9:25.

16. Worth H, Schacher C, Dethlefsen U. Concomitant therapy with cineole (eucalyptol) reduces exacerbations in COPD: a placebo-controlled doubleblind trial. Respir Res. 2009;10:69-76.

17. Vogelmeier C, Buhl R, Burghuber O, et al. Guideline for the diagnosis and treatment of COPD patientsissued by the German Respiratory Society and the German Atemwegsliga in Cooperation with the Austrian Society of Pneumology. Pneumologie. 2018;72(4):253-308. https://doi.org/10.1055/s0043-125031.

18. Onkin D, Medzhitov R. Evolution of inflammatory diseases. Curr Biol. 2012;22:R733-40.

19. Lee It, Yang CM. Inflammatory signalings involved in airway and pulmonary diseases. Mediat Inflamm. 2013;2013:791231. https://doi.org/10.1155/2013/ 791231.

20. Luo SF, Chang C, Lee IT, et al. Activation of ROS/ $\mathrm{NF}-\kappa \mathrm{B}$ and $\mathrm{Ca}^{2+} / \mathrm{CaM}$ kinase II are necessary for VCAM-1 induction in IL-1 $\beta$-treated human tracheal smooth muscle cells. Toxicol Appl Pharmacol. 2009;237(1):8-21.

21. Rider CF, Shah S, Miller-Larsson A, Giembycz MA, Newton R. Inflammatory stimuli inhibit glucocorticoid-dependent transactivation in human pulmonary epithelial cells: rescue by long-acting beta2adrenoceptor agonists. J Pharmacol Exp Ther. 2011;338(3):860-9.

22. Lee IT, Yang CM. Role of NADPH oxidase/ROS in pro-inflammatory mediators-induced airway and pulmonary diseases. Biochem Pharmacol. 2012;84(5):581-90.

23. Gaofeng Y, Wahlqvist ML, He G, Yang M, Li D. Natural products and anti-inflammatory activity. Asia Pac J Clin Nutr. 2006;15(2):143-52.

24. Borges SR, Ortiz BLS, Pereira ACM, Keita H, Carvalho JCT. Rosmarinus officinalis essential oil: a review of its phytochemistry, anti-inflammatory 
activity, and mechanisms of action involved. J Ethnopharmacol. 2019;229:29-45.

25. Quintans JSS, Shanmugaam S, Heimfarth L, et al. Monoterpenes modulating cytokines: a review. Food Chem Toxicol. 2018;123:233-57.

26. De Lavor ÉM, Fernandes AWC, de Andrade Teles $\mathrm{RB}$, et al. Essential oils and their major compounds in the treatment of chronic inflammation: a review of antioxidant potential in preclinical studies and molecular mechanisms. Oxid Med Cell Longev. 2018:6468593. https://doi.org/10.1155/2018/ 6468593.

27. Raha S, KIM SM, Lee SJ, et al. Essential oil from Korean Chameacyparis obtusa leaf ameliorates respiratory activity in Sprague-Daley rats and exhibits protection from NF- $\kappa \mathrm{B}$-induced inflammation in WI38 fibroblast cells. Int J Mol Med. 2019;43(1): 393-403. https://doi.org/10.3892/ijmm.2018.3966.

28. Greiner JF, Müller J, Zeuner MT, et al. 1,8-Cineole inhibits nuclear translocation of NF-kB p65 and NFkB-dependent transcriptional activity. Biochim Biophys Acta. 2013;1833(12):2866-78.

29. Zhao C, Sun J, Fang C, Tang F. 1,8-Cineole attenuates LPS-induced acute pulmonary inflammation in mice. Inflammation. 2014;37(2):566-72.

30. Takaishi M, Fujita F, Uchida K, et al. 1,8-Cineole, a TRPM8 agonist, is a novel natural antagonist of human TRPA1. Mol Pain. 2012;8:86. https://doi. org/10.1186/1744-8069-8-86.

31. Juergens UR, Stöber M, Schmidt-Schilling L, Kleuver $\mathrm{T}$, Vetter H. Antiinflammatory effects of eucalyptol (1,8-cineole) in bronchial asthma: inhibition of arachidonic acid metabolism in human blood monocytes ex vivo. Eur J Med Res. 1998;3(9): 407-12.

32. Juergens UR, Stöber M, Vetter H. Inhibition of cytokine production and arachidonic acid metabolism by eucalyptol (1,8-cineole) in human blood monocytes in vitro. Eur J Med Res. 1998;3(11): 508-10.

33. Varricchi G, Bagnasco D, Borriello F, Heffler E, Canonica GW. Interleukin-5 pathway inhibition in the treatment of eosinophilic respiratory disorders: evidence and unmet needs. Curr Opin Allergy Clin Immunol. 2016;16:186-200.

34. Juergens UR, Engelen T, Racké K, Stöber M, Gillissen A, Vetter H. Inhibitory activity of 1,8-cineole (eucalyptol) on cytokine production in cultured human lymphocytes and monocytes. Pulm Pharmacol Ther. 2004;17(5):281-7.
35. Beauchamp J, Kirsch F, Buettner A. Real-time breath gas analysis for pharmacokinetics: monitoring exhaled breath by on-line proton-transfer-reaction mass spectrometry after ingestion of eucalyptolcontaining capsules. J Breath Res. 2010;4(2): 026006. https://doi.org/10.1088/1752-7155/4/2/ 026006.

36. Song WJ, Kang HR, Park HW, Sohn SW. Effect of 1,8-cineole in Dermatophagoides pteronyssinus-stimulated bronchial epithelial cells and mouse model of asthma. Biol Pharm Bull. 2016;39:946-52.

37. Hosoki K, Ying S, Corrigan C, et al. Analysis of a panel of 48 cytokines in BAL fluids specifically identifies IL-8 levels as the only cytokine that distinguishes asthma and correlates inversely with FEV1. PLoS One. 2015. https://doi.org/10.1371/ journal.pone.0126035.

38. Ekstedt S, Säfholm J, Georén SK, Cardell LO. Dividing neutrophils in subsets reveals a significant role for activated neutrophils in the development of airway hyperreactivity. Clin Exp Allergy. 2019;49: 285-91.

39. Garudadri S, Woodruff PG, Han MLK, et al. Systemic markers of inflammation in smokers with symptoms despite preserved spirometry in SPIROMICS. Chest. 2019;155(5):908-17.

40. Juergens LJ, Racké K, Tuleta I, Stoeber M, Juergens UR. Anti-inflammatory effects of 1,8-cineole (eucalyptol) improve glucocorticoid effects in vitro: a novel approach of steroid-sparing add-on therapy for COPD and asthma? Synergy. 2017;5:1-8.

41. Jevnikar Z, Östling J, Ax E, et al. Epithelial IL-6 trans-signaling defines a new asthma phenotype with increased airway inflammation. J Allergy Clin Immunol.2019;143(2):577-90.

42. Juergens UR. Anti-inflammatory properties of the monoterpene 1,8-cineole: current evidence for comedication in inflammatory airway diseases. Drug Res. 2014;64(12):638-46.

43. Fischer BM, Voynow JA, Ghio AJ. COPD: balancing oxidants and antioxidants. Int J Chron Obstruct Pulmon Dis. 2015;10:261-76. https://doi.org/10. 2147/COPD.S42414.

44. Rodgman A, Perfetti TA. The chemical components of tobacco smoke. Boca Raton: CRC; 2009.

45. Ho SP, Chan-Yeung M, Chow KK, Ip MS, Mak JC. Antioxidant enzyme activities in healthy Chinese adults: influence of age, gender and smoking. Respirology. 2005;10(3):305-9.

46. Dekhuijzen PN, Aben KK, Dekker I, et al. Increased exhalation of hydrogen peroxide in patients with 
stable and unstable chronic obstructive pulmonary disease. Am J Respir Crit Care Med. 1996;154:813-6.

47. Lykkesfeldt J, Priemé H, Loft S, Poulsen HE. Effect of smoking cessation on plasma ascorbic acid concentration. BMJ.1996;313(7049):91. https://doi. org/10.1136/bmj.313.7049.91.

48. Garcia-Larsen V, Potts JF, Omenaas E, et al. Dietary antioxidants and 10-year lung function decline in adults from the ECRHS survey. Eur Respir J. 2017;50:1602286.

49. Kang JS, Han MH, Kim CM, et al. Schisandrae semen essential oil attenuates oxidative stress-induced cell damage in $\mathrm{C} 2 \mathrm{C} 12$ murine skeletal muscle-induced cells through Nrf2-mediated upregulation of HO-1. Int J Mol Med. 2015;35(2): 453-9.

50. Porres-Martinez M, González-Burgos E, Carretero ME, Gómez-Serranillos MP. Protective properties of Salvia lavandulifolia Vahl. essential oil against oxidative stress-induced neuronal injury. Food Chem Toxicol. 2015;80:154-62.

51. Pérez-Rosés R, Risco E, Vila R, Peñalver P, Cañigueral S. Biological and nonbiological antioxidant activity of some essential oils. J Agric Food Chem. 2016;64(23):4716-24.

52. Juergens LJ, Tuleta I, Stoeber M, Racké K, Juergens UR. Regulation of monocyte redox balance by 1,8 cineole (eucalyptol) controls oxidative stress and pro-inflammatory responses in vitro: a new option to increase the antioxidant effects of combined respiratory therapy with budesonide and formoterol? Synergy. 2018;7:1-9. https://doi.org/10. 1016/j.synres.2018.05.001.

53. Montuschi P, Collins JV, Ciabattoni G, et al. Exhaled 8-isoprostane as an in vivo biomarker of lung oxidative stress in patients with COPD and healthy smokers. Am J Respir Crit Care Med. 2000;162:1175-7.

54. Barnes PJ. Identifying molecular targets for new drug development for chronic obstructive pulmonary disease: what does the future hold. Semin Respir Crit Care Med. 2015;36(4):508-22.

55. Kluchová Z, Petrásová D, Joppa P, Dorková Z, Tkávcoá $\mathrm{R}$. The association between oxidative stress and obstructive lung impairment in patients with COPD. Physiol Res. 2007;56(1):51-6.

56. Bezerra FS, Santos Valenca S, et al. $\alpha$-Tocopherol and ascorbic acid supplementation reduced acute lung inflammatory response by cigarette smoke in mouse. Nutrition. 2006;22:1192-12001.
57. Tuleta I, Stöckigt F, Juergens UR, et al. Intermittent hypoxia contributes to the lung damage by increased oxidative stress, inflammation, and disbalance in protease/antiprotease system. Lung. 2016;194(6):1015-20. https://doi.org/10.1007/ s00408-016-9946-4.

58. Alam A, Majumdar RS. Anitoxidant activity of essential oil of three cultivars of Amomum subulatum and standardization of high performance thin layer chromatography (HPTLC) method for the estimation of 1,8-cineole. Afr $\mathrm{J}$ Biotechnol. 2016;17(36):1129-37.

59. Ballester-Costa C, Sendra E, Fernández-López J, Pérez-Álvarez JA, Viuda-Martos M. Assessment of antioxidant and antibacterial properties on meat homogenates of essential oils obtained from four thymus species achieved from organic growth. Foods. 2017;28;6(8). https://doi.org/10.3390/ foods6080059.

60. Kennedy-Feitosa E, Tiemi Okuro R, Pinho Ribeiro V, et al. Eucalyptol attenuates cigarette smoke-induced acute lung inflammation and oxidative stress in the mouse. Pulm Pharmacol Ther. 2016;41:11-8.

61. De Lima Gondim F, Silveira Serra D, Avila S. Effects of eucalyptol in respiratory system mechanics on acute lung injury after exposure to short-term cigarette smoke. Respir Phsiol Neurobiol. 2019;266(8):33-8. https://doi.org/10.1016/j.resp. 2019.04.007.

62. Dua K, Malyla V, Singhvi G, et al. Increasing complexity and interactions of oxidative stress in chronic respiratory diseases: an emerging need for novel drug delivery systems. Chem Biol Interact. 2019;299:168-78.

63. Dozor AJ. The role of oxidative stress in the pathogenesis and treatment of asthma. Ann N Y Acad Sci. 2010;1203:133-7. https://doi.org/10. $1111 /$ j.1749-6632.2010.05562.

64. Faner R, Sibila O, Agustí A, et al. The microbiome in respiratory medicine: current challenges and future perspectives. Eur Respir J. 2017; 49:1602086.

65. Dickson RP, Martinez FJ, Huffnagle GB. The role of the microbiome in exacerbations of chronic lung diseases. Lancet. 2014;384:691-702.

66. Segal LN, Clemente JC, Wu BG, et al. Randomised, double-blind, placebo-controlled trial with azithromycin selects for anti-inflammatory microbial metabolites in the emphysematous lung. Thorax. 2017;72(1):3-22.

67. Baines KJ, Wright TK, Gibson PG, Powell H, Hansbro PM, Simpson JL. Azithromycin treatment modifies airway and blood gene expression 
networks in neutrophilic COPD. ERS Open Res. 2018;4:00031-2018. 23120541.00031-2018.

68. Leitao Filho FS, Alotaibi NM, Ngan D, et al. Sputum microbiome is associated with 1-year mortality following COPD hospitalizations. Am J Respir Crit Care Med. 2019;199(10):1205-13.

69. Aldoghaim FS, Flematti GR, Hammer KA. Antimicrobial activity of several cineole-rich Australian eucalyptus essential oils. Microorganisms 2018. https://doi.org/10.3390/microorganisms6040122.

70. Schürmann M, Oppel F, Gottschalk M, et al. The therapeutic effect of 1,8-cineole on pathogenic bacteria species present in chronic rhinosinusitis. Front Microbiol. 2019;10.2325. https://doi.org/10. 3389/fmicb.2019.02325.

71. Merghni A, Noumi E, Hadded O, et al. Assessment of the antibiofilm and antiquorum sensing activities of Eucalyptus globulus essential oil and its main component 1,8-cineole against methicillin-resistant Staphylococcus aureus strains. Microb Pathog. 2018;118:74-80.

72. Jäger W, Nasal B, Nasel C, et al. Pharmacokinetic studies of the fragrance compound 1,8-cineole in humans during inhalation. Chem Senses. 1996;4: 477-80.

73. Sadlon AE, Lamson DW. Immune-modifying and antimicrobial effects of eucalyptus oil and simple inhalation devices. Altern Med Rev. 2010;15(1): 33-47.

74. Elaissi A, Abid NBS, Rouis Z, et al. Chemical composition of 8 eucalyptus species' essential oils and the evaluation of their antibacterial, antifungal and antiviral activities. BMC Complement Altern Med. 2012;12:81. https://doi.org/10.1186/1472-6882-1281.

75. Mika M, Nita I, Morf L, et al. Microbial and host immune factors as drivers of COPD. ERJ Open Res. 2018;4:00015-2018. https://doi.org/10.1183/ 23120541.00015-2018.

76. Östling J, van Geest M, Schofield JPR, et al. IL-17high asthma with features of a psoriasis immunophenotype. J Allergy Clin Immunol. 2019. https://doi.org/10.1016/j.jaci.2019.03.027.

77. Uzun S, Djamin RS, Kluytmans JA, et al. Azithromycin maintenance treatment in patients with frequent exacerbations of chronic obstructive pulmonary disease (COLUMBUS): a randomised, double-blind, placebo-controlled trial. Lancet Respir Med. 2014;2:361-8.
78. Seemungal TA, Wilkinson TM, Hurst JR, Perera WR, Sapsford RJ, Wedzicha JA. Long-term erythromycin therapy is associated with decreased chronic obstructive pulmonary disease exacerbations. Am J Respir Crit Care Med. 2008;178:1139-47.

79. Cazzola M, Calzetta L, Page C, et al. Influence of $N$ acetylcysteine on chronic bronchitis or COPD exacerbations: a meta-analysis. Eur Respir Rev. 2015;24:451-61.

80. JolliffeDA, Greenberg L, Hooper RL, et al. Vitamin D to prevent exacerbations of COPD: systemic review and meta-analysis of individual participant data from randomised controlled trials. Thorax 2019;74(4):337-345. https://doi.org/10.1136/ thoraxjnl-2018-212092.

81. Ian N, Luo G, Yang X, et al. 25-Hydroxyvitamin D3deficiency enhances oxidative stress and corticoid resistance in severe asthma exacerbations. PLoS One. 2014;9(11):e111599.

82. Suzaki I, Asano K, Shikama Y, Hamasaki T, Kanel A, Suzaki H. Suppression of IL-8 production from airway cells by tiotropium bromide in vitro. Int $\mathrm{J}$ Chron Obstruct Pulmon Dis. 2011;6:439-48.

83. Kistemaker LE, Bos IS, Menzen MH, Maarsingh $\mathrm{H}$, Meurs H, Gosens R. Combination therapy of tiotropium and ciclesonide attenuates airway inflammation and remodeling in a guinea pig model of chronic asthma. Respir Res. 2016;17:13. https://doi. org/10.1186/s12931-016-0327-6.

84. Bastos VP, Brito TS, Lima FJ. Inhibitory effect of 1,8cineole on guinea-pig airway challenged with obalbumin involves a preferential action on electromechanical coupling. Clin Exp Pharmacol Physiol. 2009;36(11):1120-6.

85. Singh D, D’Urzo AD, Chuecos F, Munos A, Garcia Gil E. Reduction in clinically important deterioration in chronic obstructive pulmonary disease with aclidinium/formoterol. Respir Res. 2017;18(1):106. https://doi.org/10.1186/s12931-017-0583-0.

86. Calverley PM, Anderson JA, Celli B, et al. Salmeterol and fluticasone propionate and survival in chronic obstructive pulmonary disease. $\mathrm{N}$ Engl J Med. 2007;356(8):775-89.

87. Wedzicha JA, Singh D, Tsiligianni I, et al. Treatment response to indacaterol/glycopyrronium versus salmeterol/fluticasone in exacerbating COPD patients by gender: a post hoc analysis in the Flame study. Respir Res. 2019;20(1):4. https://doi.org/10.1186/ s12931-019-0972-7.

88. Szafranski W, Cukier A, Ramirez A, et al. Efficacy and safety of budesonide/formoterol in the 
management of chronic obstructive pulmonary disease. Eur Respir J. 2003;21(1):74-81.

89. Cazzola M, Santus P, Di Marco F, et al. Bronchodilator effect of an inhaled combination therapy with salmeterol + fluticasone and formoterol + budesonide in patients with COPD. Respir Med. 2003;97(5):453-7.

90. Burge PS, Calverley PM, Jones PW, Spencer S, Anderson JA, Maslen TK. Randomised, doubleblind, placebo-controlled study of fluticasone propionate in patients with moderate to severe chronic obstructive pulmonary disease: the ISOLDE trial. BMJ. 2000;320(7245):1297-303.

91. Niewoehner DE, Rice K, Cote C, et al. Prevention of exacerbations of chronic obstructive pulmonary disease with tiotropium, a once-daily inhaled anticholinergic bronchodilator: a randomized trial. Ann Intern Med. 2005;143(5):317-26.

92. Tashkin DP, Celli B, Senn S, et al. A 4-year trial of tiotropium in chronic obstructive pulmonary disease. N Engl J Med. 2008;359(15):1543-54.

93. Calverly PM, Rabe KF, Goehring UM, Kristiansen S, Fabbri LM, Martinez FJ. Roflumilast in symptomatic chronic obstructive pulmonary disease: two randomised clinical trials. Lancet. 2009;374(9691): 685-94.

94. Singh D, Maleki-Yazdi MR, Tombs L, Iqbal A, Fahy WA, Naya I. Prevention of clinically important deteriorations in COPD with umeclidinium/vilanterol. Int J Chron Obstruct Pulmon Dis. 2016;11: 1413-24. 